Research Paper

\title{
Overexpression of the PSAT1 Gene in Nasopharyngeal Carcinoma Is an Indicator of Poor Prognosis
}

\author{
Kuang-Ming Liao', Tung-Bo Chao 2,3, Yu-Feng Tian, ${ }^{4,5}$, Ching-Yih Lin ${ }^{6,7}$, Sung-Wei Lee ${ }^{8}$, Hua-Ying Chuang ${ }^{1}$, \\ Ti-Chun Chan ${ }^{9}$, Tzu-Ju Chen ${ }^{9}$, Chung-Hsi Hsing10, Ming-Jen Sheu' ${ }^{6}$, Chien-Feng Li ${ }^{9}, 11,12,13, \bowtie$ \\ 1. Department of Internal Medicine, Chi Mei Medical Center, Chiali, Taiwan \\ 2. Departments of Colorectal Surgery, Yuan's General Hospital, Kaohsiung, Taiwan. \\ 3. Department of Health Business Administration, Meiho University, Pingtung, Taiwan \\ 4. Division of General Surgery, Chi Mei Medical Center, Tainan, Taiwan \\ 5. Department of Health and Nutrition, Chia Nan University of Pharmacy \& Science, Tainan, Taiwan \\ 6. Department of Internal Medicine, Chi Mei Medical Center, Tainan, Taiwan \\ 7. Department of Leisure, Recreation, and Tourism Management, Southern Taiwan University of Science and Technology, Tainan, Taiwan \\ 8. Department of Radiation Oncology, Chi-Mei Medical Center, Liouying, Tainan, Taiwan \\ 9. Department of Pathology, Chi Mei Medical Center, Tainan, Taiwan \\ 10. Department of Anesthesiology, Chi Mei Medical Center, Tainan, Taiwan \\ 11. National Institute of Cancer Research, National Health Research Institutes, Tainan, Taiwan \\ 12. Department of Biotechnology, Southern Taiwan University of Science and Technology, Tainan, Taiwan \\ 13. Institute of Clinical Medicine, Kaohsiung Medical University, Kaohsiung, Taiwan \\ $\square$ Corresponding author: Chien-Feng Li, M.D., Ph.D., Division of Clinical Pathology, Chi Mei Medical Center, 901 Chunghwa Road, Yung Kang Dist., Tainan \\ County 710, TAIWAN, Tel: +886-6-2812811 ext. 53680, Fax: +886-6-2511235, E-mail: angelo.p@yahoo.com.tw.
}

() Ivyspring International Publisher. Reproduction is permitted for personal, noncommercial use, provided that the article is in whole, unmodified, and properly cited. See http://ivyspring.com/terms for terms and conditions.

Received: 2016.02.12; Accepted: 2016.04.26; Published: 2016.05.25

\begin{abstract}
Purpose: Nasopharyngeal carcinoma (NPC) is a common cancer in southern China and Southeast Asia, but risk stratification and treatment outcome in NPC patients remain suboptimal. Our study identified and validated metabolic drivers that are relevant to the pathogenesis of NPC using a published transcriptome. Phosphoserine aminotransferase 1 (PSATI) is an enzyme that is involved in serine biosynthesis, and its overexpression is associated with colon cancer, non-small cell lung cancer and breast cancer. However, its expression has not been systemically evaluated in patients with NPC.

Materials and Methods: We evaluated two public transcriptomes of NPC tissues and benign nasopharyngeal mucosal epithelial tissues that deposited in the NIH Gene Expression Omnibus database under accession number GSE34574 and GSE12452. We also performed immunohistochemical staining and assessment of PSATI in a total of 124 NPC patients received radiotherapy and were regularly followed-up until death or loss. The endpoints analyzed were local recurrence-free survival (LRFS), distant metastasis-free survival (DMFS), disease-specific survival (DSS), and overall survival (OS).

Results: We retrospectively evaluated 124 patients with NPC and found that high PSATI expression was associated with poor prognosis of NPC and indicator of advanced tumor stage. High PSATI expression also correlated with an aggressive clinical course, with significantly shorter DSS (HR $=2.856$, $95 \% \mathrm{Cl} 1.599$ to 5.101 ), DMFS (HR=3.305, 95\% $\mathrm{Cl} 1.720$ to 6.347 ), LRFS (HR= $2.834,95 \% \mathrm{Cl} 1.376$ to 5.835), and $\mathrm{OS} H R=2.935,95 \% \mathrm{Cl} 1.646-5.234)$ in multivariate analyses.

Conclusions: Our study showed that PSATI is a potential prognostic biomarker and higher expression of PSATI is associated with a poor prognosis in NPC.
\end{abstract}

Key words: PSAT1, Nasopharyngeal carcinoma, prognosis

\section{Introduction}

Nasopharyngeal carcinoma (NPC) is a common malignancy that originates in the nasopharynx, and it exhibits a complex biology that is not fully understood. The incidence of NPC is rare in most populations, such as Europe and the United States, but it is a common cancer in southern China and 
Southeast Asia ${ }^{1}$ and other populations, including the Middle East/North Africa and the Arctic. Genetics interact with the environment and contribute to the development of NPC because of the racial and ethnic geographical distribution of NPC worldwide².

A previous study used published data in endemic areas and demonstrated that concurrent chemoradiotherapy was an effective treatment for locally advanced NPC and improved overall survival $^{3}$. A study also showed neoadjuvant chemotherapy and concurrent chemoradiotherapy can reduce distant failure as compared with concurrent chemoradiotherapy alone ${ }^{4}$. However, the percentage of patients with distant metastases is high in NPC, and patients with distant metastases exhibit poor prognosis ${ }^{5-10}$. Accordingly, NPC management should consider individual patient differences using recognized prognostic factors. It is important to identify biomarkers that are independently associated with rapidly progressive tumors to designate an appropriate treatment.

It is getting clear that cancer cells acquire alterations in the metabolism of carbohydrates, proteins, lipids and nucleic acids to meet the requirements for rapid proliferation ${ }^{11}$. Cancer cells need high amounts of nonessential and essential amino acids to fuel essential anabolic processes. Growing evidence suggests that amino acid metabolic pathways are also chemotherapeutic targets ${ }^{12}$. We used the published transcriptome of NPC to find genes involved in tumorigenesis ${ }^{13}$ and demonstrated that phosphoserine aminotransferase 1 (PSAT1) was a prominently upregulated gene in the regulation of amino acid metabolism.

PSAT1 was observed in the brains and livers of sheep ${ }^{14}$. PSAT1 is involved in the second step of serine biosynthesis, and it converts 3-phosphohydroxypyruvate to L-phosphoserine ${ }^{15}$. PSAT1 plays an important role in metabolic functions. PSAT1 deficiency leads to seizures and acquired microcephaly ${ }^{16}$, and overexpression of PSAT1 correlates with cancer development ${ }^{17}$. However, information on the functions of PSAT1 in the regulation of cell proliferation and tumorigenesis and the association between PSAT1 overexpression and clinical implications in patients with NPC are not clear. Our study evaluated the influence of PAST1 expression on the clinical outcome of NPC patients.

\section{Materials and methods}

\section{Analysis of published transcriptomic datasets}

We evaluated one public transcriptome containing expression profiling data of (GSE34574) which contains expression profiling data deposited in the NIH Gene Expression Omnibus database. The raw CEL files of Affymetrix HUMAN Genome U133 Plus 2.0 microarray platform were imported into Nexus Expression 3 software (BioDiscovery) to analyze all probe sets without pre-selection or filtering. Supervised comparative analyses and functional profiling were performed to identify significant differentially expressed genes, and special attention was paid to pathways involved in amino acid biosynthesis in Gene Ontology (GO:0008652). Genes with $P \leqq 0.01$ and a $\log _{2}$-transformed expression fold change $>1$ were selected for further analysis. To crossly validate the findings, we also analyze another transcriptome dataset (GSE12452) for the selection of candidate gene as already been described in our previous publication ${ }^{18}$.

\section{Patients and tumor specimens}

The institutional review board approved the procurement of formalin-fixed NPC tissue for this study (IRB10501-006). In brief, a total of 124 formalin-fixed paraffin-embedded tissue samples from NPC patients were used for PSAT1 immunohistochemical evaluations. These patients were regularly followed up by physicians after biopsy in the Chi-Mei Medical Center. Patients who were initially diagnosed with NPC without distant metastasis underwent tissue biopsy between January 1998 and December 2002. Two pathologists (C.F. Li and T.J Chen) classified tumors by histological type based on WHO classifications ${ }^{19}$. Tumor stage was adjusted according to the American Joint Committee on Cancer Tumor-Nodes-Metastasis (TNM) classification of malignant tumors ${ }^{20}$.

\section{Immunohistochemical staining and assessment of PSAT 1}

Formalin-fixed, paraffin-embedded tissue samples were cut into 4 - $\mu$ m-thick sections. Paraffin-embedded tissues were deparaffinized using xylene, rehydrated in ethanol, and heated in a microwave using methods described in our previous study ${ }^{21}$. Tissue samples were washed in Tris-buffered saline for $15 \mathrm{~min}$, and slides were incubated with a primary monoclonal antibody against PSAT1 (1:100; Abcam).

\section{Treatment and follow-up}

All 124 NPC patients received a complete course of 3-dimensional radiotherapy (3DRT) in a constant protocol and were regularly followed-up until death or loss. The mean follow-up duration was 3 years. Patients with stage II-IV disease received concurrent cisplatin-based chemotherapy in addition to radiotherapy. 


\section{Statistical analysis}

The SPSS 14 software package was used to perform statistical data analyses. Chi-square or Fisher's exact test analyzed the relationship between PSAT1 immunohistochemical expression and various clinicopathological parameters. The endpoints analyzed were local recurrence-free survival (LRFS), distant metastasis-free survival (DMFS), disease-specific survival (DSS), and overall survival (OS) which were calculated from the starting date of radiotherapy to the date of an event. Patients lost to follow-up were censored on the latest follow-up date. Multivariate analysis was performed using the Cox proportional hazards model. We also performed Kaplan-Meier analysis to compare the survival curves in NPC patients with different groups. The log-rank test was used to investigate differences in survival times between two groups. A $P$-value $<0.05$ was considered statistically significant.

\section{Results}

PSATI was the most significantly upregulated gene associated with amino acid biosynthetic pathway in NPC.

Table 1 provides a summary of 8 significant differentially expressed genes associated with amino acid biosynthesis in the transcriptome of nasopharyngeal carcinomas (GSE34574). Of these, ASNS, PSPH, and PSAT1 exhibited upregulated mRNA expression and PSAT1 demonstrated the most significant upregulation (Logs ratio $=4.2088, P<0.0001$, Fig. 1). Interestingly, we also confirmed PSAT1 as the most significantly upregulated gene in an independent GEO dataset (GSE12452) which discloses PSAT1 upregulaiton is most associated with the development of NPC (tumor versus non-tumor, log2 ratio=2.0392, $P<0.0001)$ in those associated with amino acid biosynthesis. Accordingly, we further evaluated the clinicopathological significance of PSAT1 expression by immunohistochemistry.

Table 1. Summary of differentially expressed genes associated with amino acid biosynthesis in the transcriptome of nasopharyngeal carcinomas (GSE34574)

\begin{tabular}{|c|c|c|c|c|c|c|}
\hline Probe & $\begin{array}{l}\text { Compari- } \\
\text { son } 1 \text { Log } \\
\text { ratio (NPC } \\
\text { vs. Non- } \\
\text { tumor } \\
\text { tissue) }\end{array}$ & p-value & $\begin{array}{l}\text { Gene } \\
\text { Symbol }\end{array}$ & Gene Name & Biological Process & Molecular Function \\
\hline 223062_s_at & 4.2088 & $<0.0001$ & PSAT1 & $\begin{array}{l}\text { phosphoserine } \\
\text { aminotransferase } 1\end{array}$ & $\begin{array}{l}\text { L-serine biosynthetic process, amino acid } \\
\text { biosynthetic process, metabolic process, } \\
\text { pyridoxine biosynthetic process }\end{array}$ & $\begin{array}{l}\text { catalytic activity, phosphoserine transaminase } \\
\text { activity, pyridoxal phosphate binding, } \\
\text { transaminase activity, transferase activity }\end{array}$ \\
\hline 205047_s_at & 3.4002 & $<0.0001$ & ASNS & asparagine synthetase & $\begin{array}{l}\text { amino acid biosynthetic process, asparagine } \\
\text { biosynthetic process, glutamine metabolic } \\
\text { process, metabolic process }\end{array}$ & $\begin{array}{l}\text { asparagine synthase (glutamine-hydrolyzing) } \\
\text { activity, ligase activity }\end{array}$ \\
\hline 217956_s_at & 2.3727 & 0.0031 & ENOPH1 & enolase-phosphatase 1 & $\begin{array}{l}\text { amino acid biosynthetic process, metabolic } \\
\text { process, methionine biosynthetic process }\end{array}$ & $\begin{array}{l}\text { catalytic activity, hydrolase activity, magnesium } \\
\text { ion binding, metal ion binding, phosphoglycolate } \\
\text { phosphatase activity }\end{array}$ \\
\hline 203774_at & 2.0694 & 0.0004 & MTR & $\begin{array}{l}\text { 5-methyltetrahydrofola } \\
\text { te-homocysteine } \\
\text { methyltransferase }\end{array}$ & $\begin{array}{l}\text { amino acid biosynthetic process, central } \\
\text { nervous system development, folic acid and } \\
\text { derivative biosynthetic process, methionine } \\
\text { biosynthetic process, nervous system } \\
\text { development }\end{array}$ & $\begin{array}{l}\text { cobalamin binding, cobalt ion binding, } \\
\text { dihydropteroate synthase activity, homocysteine } \\
\text { S-methyltransferase activity, metal ion binding, } \\
\text { methionine synthase activity, methyltransferase } \\
\text { activity, protein binding, transferase activity, zinc } \\
\text { ion binding }\end{array}$ \\
\hline 205048_s_at & 1.543 & 0.0047 & $P S P H$ & $\begin{array}{l}\text { phosphoserine } \\
\text { phosphatase }\end{array}$ & $\begin{array}{l}\text { L-serine biosynthetic process, L-serine } \\
\text { metabolic process, amino acid biosynthetic } \\
\text { process, cell proliferation, metabolic process }\end{array}$ & $\begin{array}{l}\text { catalytic activity, hydrolase activity, magnesium } \\
\text { ion binding, phosphoric monoester hydrolase } \\
\text { activity, phosphoserine phosphatase activity, } \\
\text { protein binding }\end{array}$ \\
\hline 203576_at & -1.3603 & 0.0002 & BCAT2 & $\begin{array}{l}\text { branched chain } \\
\text { aminotransferase 2; } \\
\text { mitochondrial }\end{array}$ & $\begin{array}{l}\text { amino acid biosynthetic process, branched } \\
\text { chain family amino acid biosynthetic process, } \\
\text { branched chain family amino acid catabolic } \\
\text { process, branched chain family amino acid } \\
\text { metabolic process, metabolic process }\end{array}$ & $\begin{array}{l}\text { branched-chain-amino-acid transaminase activity, } \\
\text { catalytic activity, transaminase activity, transferase } \\
\text { activity }\end{array}$ \\
\hline 204608_at & -1.3908 & 0.0008 & $A S L$ & argininosuccinate lyase & $\begin{array}{l}\text { amino acid biosynthetic process, arginine } \\
\text { biosynthetic process, arginine biosynthetic } \\
\text { process via ornithine, arginine catabolic } \\
\text { process, urea cycle }\end{array}$ & $\begin{array}{l}\text { argininosuccinate lyase activity, catalytic activity, } \\
\text { lyase activity }\end{array}$ \\
\hline 207076_s_at & -3.6325 & 0.0001 & ASS1 & $\begin{array}{l}\text { argininosuccinate } \\
\text { synthetase } 1\end{array}$ & $\begin{array}{l}\text { amino acid biosynthetic process, arginine } \\
\text { biosynthetic process, urea cycle }\end{array}$ & $\begin{array}{l}\text { ATP binding, argininosuccinate synthase activity, } \\
\text { ligase activity, nucleotide binding, protein binding }\end{array}$ \\
\hline
\end{tabular}




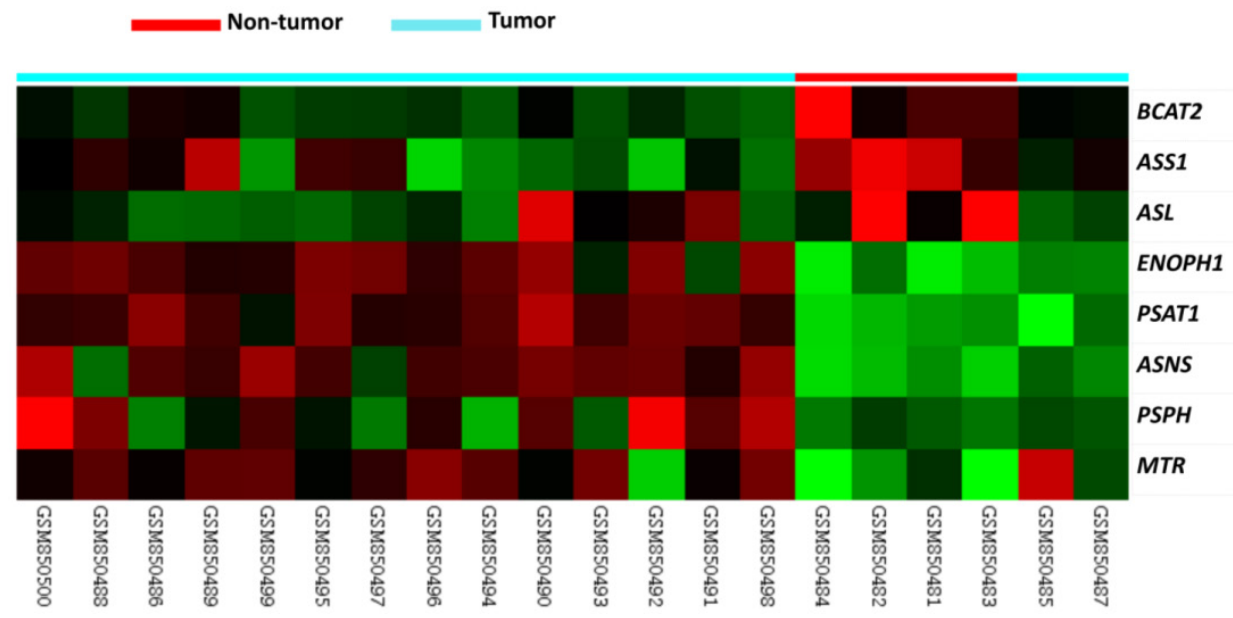

Figure 1. Published transcriptomic datasets of NPC versus benign nasopharyngeal tissues samples were evaluated. PSATI was an upregulated gene in the regulation of amino acid biosynthesis in the clustering analysis. Nasopharyngeal carcinoma (blue lines) and benign tissue (red lines) specimens are indicated at the top of the heatmap, and expression levels of upregulated and downregulated genes are expressed as a series of brightness of red and green colors, respectively. Unaltered mRNA expression is coded black.

\section{Clinicopathological features of our NPC cohort}

Table 2 shows the associations between PAST1 expression and important clinicopathological variables. The 124 cases of NPC consisted of 5 keratinizing squamous cell carcinomas, 54 non-keratinizing differentiated carcinomas, and 65 undifferentiated carcinomas. There were 95 males and 29 females, and 26 cases were older than 60 years of age. Thirty-eight cases were classified as stages I and II, and 85 cases were classified as stages III and IV. The mean follow-up period was 3 years, and the median duration to tumor-associated mortality was 2 years. The median durations to distal metastasis and local recurrence were 10 and 16 months, respectively.

\section{Immunohistochemical expression of PSATI and associations with clinicopathological features and treatment outcomes}

Low PAST1 expression was significantly associated with T1-T2 classification $(P=0.024)$ and stages I-II classification $(P=0.019)$, but it was not related to histological grade. Of all important clinicopathological paraneters, T3-4 status, N2-3 status and AJCC III-IV stages, and high PAST1 expression were all significantly predictive of worse outcomes for the three survival endpoints analyzed in univariate analyses (Table 3, Fig. 3). AJCC III-IV stages remained prognostically independent for DSS $(P=0.041$, hazard ratio $[\mathrm{HR}]=2.072)$, LRFS $(P=0.028$, $\mathrm{HR}=2.935)$, and $\mathrm{OS}(P=0.036, \mathrm{HR}=2.108)$ in multivariate comparisons, but it lost statistical significance for DMeFS (Table 4). Moreover, high PAST1 expression also predictive a more aggressive clinical course, with significantly shorter DSS (HR=
$2.856,95 \%$ CI 1.599 to 5.101$), \mathrm{DMeFS}(\mathrm{HR}=3.305,95 \%$ CI 1.720 to 6.347$)$, LRFS (HR= 2.834, 95\% CI 1.376 to 5.835), and $\mathrm{OS}(\mathrm{HR}=2.935,95 \%$ CI 1.646-5.234) in multivariate analyses.

Table 2. Associations between PSATI expression with other important clinicopathological variables.

\begin{tabular}{|c|c|c|c|c|}
\hline \multirow[t]{2}{*}{ Parameters } & \multirow[t]{2}{*}{ Category } & \multicolumn{2}{|c|}{ PSAT1 Exp. } & \multirow[t]{2}{*}{ p-value } \\
\hline & & Low Exp. & High Exp. & \\
\hline \multirow[t]{2}{*}{ Gender } & Male & 47 & 48 & 0.832 \\
\hline & Female & 15 & 14 & \\
\hline \multirow[t]{2}{*}{ Age (years) } & $<60$ years & 47 & 51 & 0.378 \\
\hline & $>=60$ years & 15 & 11 & \\
\hline \multirow[t]{2}{*}{ Primary tumor $(\mathrm{T})$} & $\mathrm{T} 1-\mathrm{T} 2$ & 46 & 34 & $0.024^{*}$ \\
\hline & T3-T4 & 16 & 28 & \\
\hline \multirow[t]{2}{*}{ Nodal status (N) } & N0-N1 & 31 & 25 & 0.279 \\
\hline & N2-N3 & 31 & 37 & \\
\hline \multirow[t]{2}{*}{ Stage } & I-II & 25 & 13 & $0.019 *$ \\
\hline & III-IV & 37 & 49 & \\
\hline \multirow[t]{3}{*}{ Histological grade } & Keratinizing & 3 & 2 & 0.445 \\
\hline & Non-keratinizing & 30 & 24 & \\
\hline & Undifferentiated & 29 & 36 & \\
\hline
\end{tabular}

\section{Discussion}

PSAT1 is an aminotransferase that plays an important role in linking catabolic pathways (glycolysis) and amino acid (serine) biosynthesis. PSAT1 is responsible for the second step in serine synthesis, and it converts 3-phosphohydroxypyruvate to phosphoserine. Serine is an important carbon source for purine nucleotides, phosphatidylcholine, phosphatidylserine, and other cellular metabolites. Cancer cells use glucose and glutamine to support energy and anabolic metabolism 22,23, and PSAT1 is overexpressed in some cancer cells. Cancer cells use non-amino acid precursors to synthesize glycine and serine, which was first noted in lymphomas ${ }^{24}$. 
A previous study demonstrated that serine biosynthesis played an important role in bone metastatic breast cancer. Three enzymes, PSAT1, phosphoserine phosphatase $(P S P H)$ and phosphoglycerate dehydrogenase $(P H G D H)$, were responsible for the phosphorylated pathway of L-serine biosynthesis ${ }^{25}$. Jason et al. found that much of the glycolytic carbon in melanoma was redirected to serine and glycine metabolism via PHGDH. PSAT1 expression was also observed in melanoma ${ }^{26}$. PSAT1 is weakly expressed in normal colon tissue but is overexpressed in colon cancer, and its expression is associated with disease progression ${ }^{27-28}$. Yoon et al. followed 78 patients with recurrent colon cancer during a median follow-up duration of 55.5 months and found that $P H G D H$, pyruvate dehydrogenase kinase 1, and PSAT expression was significantly higher in tumor cells than normal tissue. Univariate analysis for recurrence-free survival in colon tumor cells demonstrated that pyruvate dehydrogenase kinase 2 positivity was the only positive prognostic factor, but there was no significant difference in multivariate analysis ${ }^{29}$.

Table 3. Univariate log-rank analyses.

\begin{tabular}{|c|c|c|c|c|c|c|c|c|c|c|}
\hline \multirow[t]{2}{*}{ Parameters } & \multirow[t]{2}{*}{ Category } & \multirow[t]{2}{*}{ No. of case } & \multicolumn{2}{|c|}{ DSS } & \multicolumn{2}{|c|}{ DMeFS } & \multicolumn{2}{|c|}{ LRFS } & \multicolumn{2}{|c|}{ OS } \\
\hline & & & $\begin{array}{l}\text { No. of } \\
\text { event }\end{array}$ & p-value & $\begin{array}{l}\text { No. of } \\
\text { event }\end{array}$ & p-value & $\begin{array}{l}\text { No. of } \\
\text { event }\end{array}$ & p-value & $\begin{array}{l}\text { No. of } \\
\text { event }\end{array}$ & $P$-value \\
\hline \multirow[t]{2}{*}{ Gender } & Male & 95 & 45 & 0.7870 & 38 & 0.6128 & 30 & 0.3240 & 46 & 0.7220 \\
\hline & Female & 29 & 14 & & 11 & & 7 & & 14 & \\
\hline \multirow[t]{2}{*}{ Age (years) } & $<60$ years & 98 & 48 & 0.8600 & 42 & 0.3091 & 29 & 0.8206 & 49 & 0.8049 \\
\hline & $>=60$ years & 26 & 11 & & 7 & & 8 & & 11 & \\
\hline \multirow[t]{2}{*}{ Primary tumor $(\mathrm{T})$} & $\mathrm{T} 1-\mathrm{T} 2$ & 80 & 32 & $0.0289 *$ & 25 & $0.0085^{*}$ & 19 & $0.0180^{*}$ & 32 & $0.0204^{*}$ \\
\hline & T3-T4 & 44 & 27 & & 24 & & 18 & & 28 & \\
\hline \multirow[t]{2}{*}{ Nodal status (N) } & N0-N1 & 56 & 18 & $0.0008^{*}$ & 17 & $0.0132 *$ & 12 & $0.0160^{*}$ & 19 & $0.0011^{*}$ \\
\hline & N2-N3 & 68 & 41 & & 32 & & 25 & & 41 & \\
\hline \multirow[t]{2}{*}{ Stage } & I-II & 38 & 10 & $0.0020^{*}$ & 9 & $0.0072 *$ & 5 & $0.0026^{*}$ & 10 & $0.0020^{*}$ \\
\hline & III-IV & 86 & 49 & & 40 & & 32 & & 49 & \\
\hline \multirow[t]{2}{*}{ Histological grade } & Keratinizing/Non-keratinizing & 47 & 20 & 0.1980 & 17 & 0.2753 & 15 & 0.9521 & 20 & 0.1522 \\
\hline & Undifferentiated & 77 & 39 & & 32 & & 22 & & 40 & \\
\hline \multirow[t]{2}{*}{ PAST1 Exp. } & Low Exp. & 60 & 17 & $<0.0001 *$ & 13 & $<0.0001 *$ & 11 & $0.0002 *$ & 17 & $<0.0001^{*}$ \\
\hline & High Exp. & 64 & 42 & & 36 & & 26 & & 42 & \\
\hline
\end{tabular}

*, Statistically significant; DSS, disease-specific survival; DMeFS, distal metastasis-free Survival; LRFS, local recurrence-free survival; OS, overall survival.

Table 4. Multivariate survival analyses

\begin{tabular}{|c|c|c|c|c|c|c|c|c|c|c|c|c|c|}
\hline \multirow[t]{2}{*}{ Parameter } & \multirow[t]{2}{*}{ Category } & \multicolumn{3}{|c|}{ DSS } & \multicolumn{3}{|c|}{ DMeFS } & \multicolumn{3}{|c|}{ LRFS } & \multicolumn{3}{|c|}{ os } \\
\hline & & H.R & $95 \% \mathrm{CI}$ & p-value & H.R & $95 \% \mathrm{CI}$ & p-value & H.R & $95 \% \mathrm{CI}$ & p-value & H.R & $95 \% \mathrm{CI}$ & p-value \\
\hline \multirow[t]{2}{*}{ Stage } & I-II & 1 & - & $0.041^{*}$ & 1 & - & 0.093 & 1 & - & $0.028^{*}$ & 1 & - & $0.036^{*}$ \\
\hline & III-IV & 2.072 & $1.030-4.168$ & & 1.890 & $0.900-3.969$ & & 2.935 & 1.122-7.677 & & 2.108 & $1.048-4.238$ & \\
\hline \multirow[t]{2}{*}{ PAST1 Exp. } & Low Exp. & 1 & - & $<0.001^{*}$ & 1 & & $<0.001^{*}$ & 1 & - & $0.005^{*}$ & 1 & - & $<0.001$ \\
\hline & High Exp. & 2.856 & 1.599-5.101 & & 3.305 & $1.720-6.347$ & & 2.834 & $1.376-5.835$ & & 2.935 & $1.646-5.234$ & \\
\hline
\end{tabular}

*, Statistically significant; DSS, disease-specific survival; DMeFS, distal metastasis-free Survival; LRFS, local recurrence-free survival; OS, overall survival
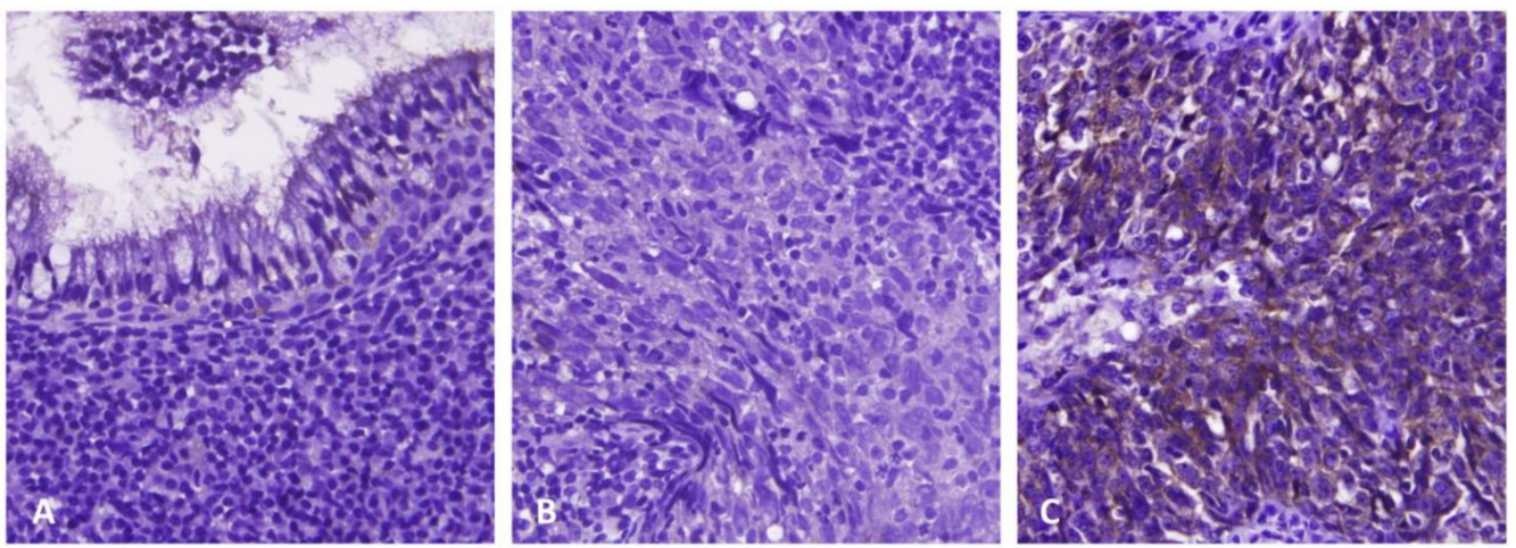

Figure 2. Immunoexpression of PSATI in benign nasopharyngeal epithelial tissue (A), low-stage (B), and high-stage (C) nasopharyngeal carcinomas, respectively. Immunohistochemically, PSATI expression was barely detected in benign nasopharyngeal epithelial tissue and low-stage nasopharyngeal carcinoma, but it significantly upregulated in high-stage nasopharyngeal carcinoma 

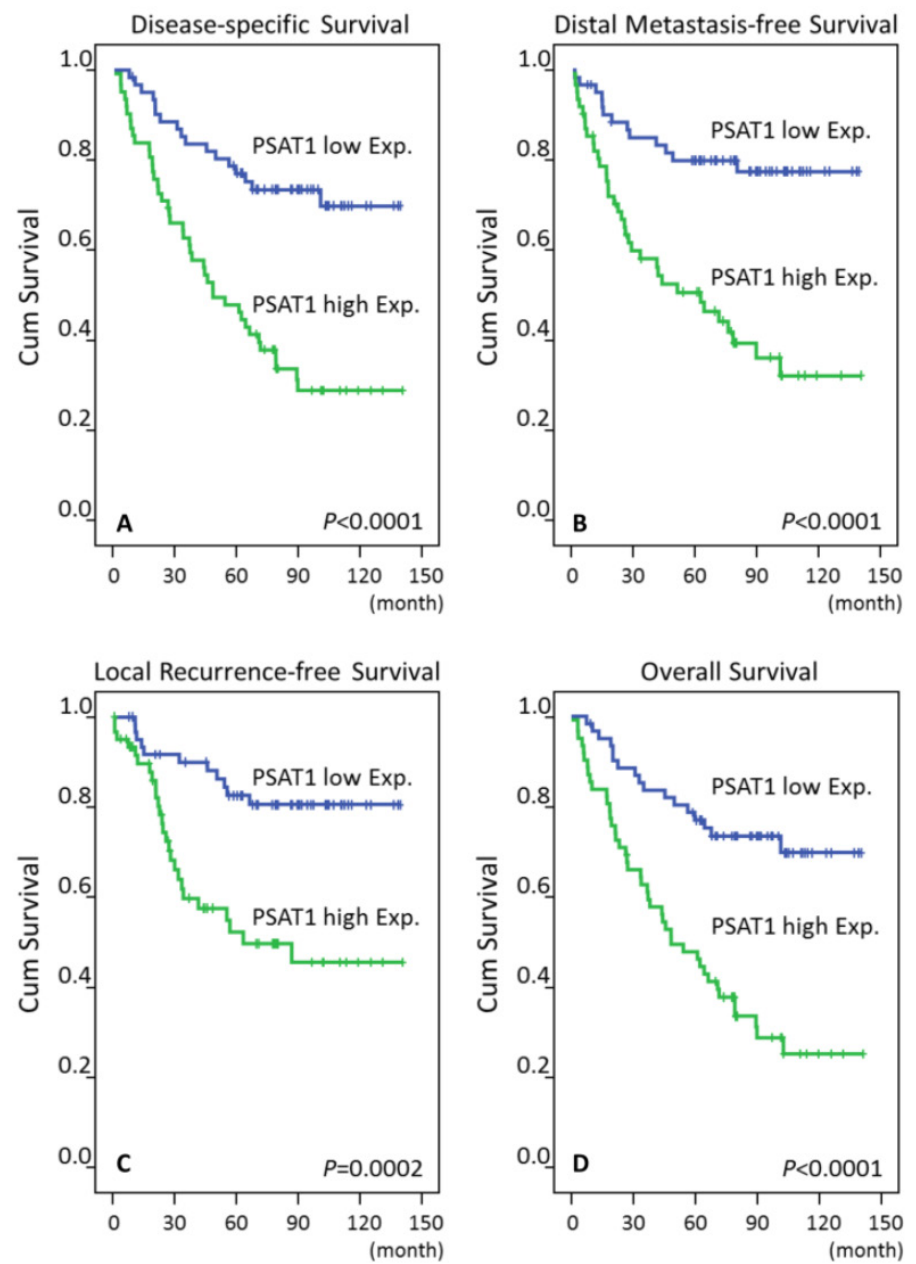

Figure 3. Log-rank test revealed that PSATI overexpression was predictive of poor prognosis, including disease-specific survival, distant metastasis-free survival, local recurrence-free survival, and overall survival.

The regulatory mechanism of PSAT1 expression remains largely unknown. But it has been reported that MicroRNA (MiR)-340, playing a role in tumor suppression in esophageal squamous cell carcinoma, inhibits tumor proliferation via targeting of PSAT1, and PSAT1. In this manner, MiR-340 is involved in cancer cell proliferation and invasion in esophageal squamous cell carcinoma, suggesting a possible regulatory mechanism of PSAT1 expression ${ }^{30}$. Few if any previous reports have disclosed the role of PSAT1 in regulating cell proliferation. It is interesting that PSAT1 is overexpressed in non-small cell lung cancer, and it is involved in tumor cell proliferation and cell cycle progression. PSAT1 enhances G1 activity via modulation of cyclin D1 degradation and Rb-E2F pathway activity, suggesting its unique intracellular signaling axis ${ }^{31}$.

Our study found that high PSAT1 expression was a potent prognostic factor for DSS, DMeFS, LRFS and OS in NPC patients. The identification of biomarkers that independently correlate with tumor aggressiveness is important for the individualized management of high risk NPC. We confirmed increased hazard ratios of DSS, DMeFS, LRFS and OS in NPC patients with advanced stages (III-IV). A significant association between PSAT1 expression, primary tumor size, nodal status and AJCC stage of NPC was observed. Therefore, we hypothesized that high PSAT1 expression may represent NPC progression via an amino acid biosynthetic process.

PSAT1 overexpression in colon and breast cancers correlates with advanced tumor stage, chemoresistance and poor prognosis to endocrine therapy ${ }^{28}$. A high expression level of PSAT1 was associated with an advanced stage of NPC and poor prognosis compared to the NPC patients with low PSAT1 expression in our study. The role of PSAT1 in tumorigenesis and NPC development and progression and the use of PSAT1 as a treatment target require further investigation.

In conclusion, PSAT1 was overexpressed in the transcriptome of NPC, and NPC protein was identified in NPC tissue using immunohistochemistry. PSAT1 was associated with 


\section{advanced tumor stage, and it independently predicted a poor prognosis of NPC.}

\section{Competing Interests}

The authors have declared that no competing interest exists.

\section{References}

1. Parkin DM, Whelan SL, Ferlay J, et al. Cancer incidence in five continents, vol. VIII. IARC scientific publications No. 155. Lyon: IARC; 2002.

2. Chang ET, Adami HO.The enigmatic epidemiology of nasopharyngeal carcinoma. Cancer Epidemiol Biomarkers Prev. 2006;15:1765-77

3. Li Zhang, Chong Zhao, Bijesh Ghimire, et al. The role of concurrent chemoradiotherapy in the treatment of locoregionally advanced nasopharyngeal carcinoma among endemic population: a meta-analysis of the phase iii randomized trials. BMC Cancer. 2010; $10: 558$

4. Chen YP, Guo R, Liu N, et al. Efficacy of the Additional Neoadjuvant Chemotherapy to Concurrent Chemoradiotherapy for Patients with Locoregionally Advanced Nasopharyngeal Carcinoma: a Bayesian Network Meta-analysis of Randomized Controlled Trials. J Cancer. 2015;6:883-92.

5. Razak AR, Siu LL, Liu FF, et al. Nasopharyngeal carcinoma: the next challenges. Eur J Cancer. 2010;46:1967-78.

6. Khanfir A, Frikha M, Ghorbel A, et al. Prognostic factors in metastatic nasopharyngeal carcinoma. Cancer Radiother. 2007;11:461-4.

7. Ng WT, Lee MC, Hung WM, et al. Clinical outcomes and patterns of failure after intensity-modulated radiotherapy for nasopharyngeal carcinoma. Int J Radiat Oncol Biol Phys. 2011;79:420-8.

8. Hui EP, Leung SF, Au JS, et al. Lung metastasis alone in nasopharyngeal carcinoma: a relatively favorable prognostic group. A study by the Hong Kong Nasopharyngeal Carcinoma Study Group. Cancer. 2004;101:300-6.

9. Teo PM, Kwan WH, Lee WY, et al. Prognosticators determining survival subsequent to distant metastasis from nasopharyngeal carcinoma. Cancer. 1996;77:2423-31.

10. Khanfir A, Frikha M, Ghorbel A, et al. Metastatic nasopharyngeal carcinoma: clinical study and therapeutic results of 95 cases. Cancer Radiother. 2006;10:545-9.

11. Cairns RA, Harris IS, Mak TW. Regulation of cancer cell metabolism. Nat Rev Cancer. 2011;11:85-95.

12. Daniel A. Tennant, Raúl V. Durán, Eyal Gottlieb. Targeting metabolic transformation for cancer therapy. Nat Rev Cancer. 2010;10:267-77.

13. Sengupta S, den Boon JA, Chen IH, et al. Genomewide expression profiling reveals EBV-associated inhibition of MHC class I expression in nasopharyngeal carcinoma. Cancer Res. 2006;66:7999-8006.

14. Baek JY, Jun DY, Taub D, et al. Characterization of human phosphoserine aminotransferase involved in the phosphorylated pathway of L-serine biosynthesis. Biochem J. 2003;373:191-200.

15. Basurko MJ, Marche M, Darriet M, et al. Phosphoserine aminotransferase, the second step-catalyzing enzyme for serine biosynthesis. IUBMB Life. 1999;48:525-9.

16. Hart CE, Race V, Achouri Y, et al. Phosphoserine aminotransferase deficiency: a novel disorder of the serine biosynthesis pathway. Am J Hum Genet. 2007;80:931-7.

17. Vié N, Copois V, Bascoul-Mollevi C, et al. Overexpression of phosphoserine aminotransferase PSAT1 stimulates cell growth and increases chemoresistance of colon cancer cells. Mol Cancer. 2008;7:14.

18. Chen TJ, Lee SW, Lin LC, et al. Cyclin-dependent kinase 4 overexpression is mostly independent of gene amplification and constitutes an independent prognosticator for nasopharyngeal carcinoma. Tumour Biol. 2014;35:7209-16.

19. Leon Barnes, John W. Eveson, Peter Reichart, et al. Nasopharyngeal carcinoma World Health Organization classification of tumors-pathology and genetics: head and neck tumors. Lyon: IARC Press; 2005.

20. Edge SB, Byrd DR, Compton CC, et al. AJCC Cancer Staging Manual. 7th ed. New York, NY: Springer; 2010.

21. Lan J, Tai HC, Lee SW, et al. Deficiency in expression and epigenetic DNA Methylation of ASS1 gene in nasopharyngeal carcinoma: negative prognostic impact and therapeutic relevance. Tumour Biol. 2014;35:161-9.

22. Rajagopalan KN, DeBerardinis RJ. Role of glutamine in cancer: therapeutic and imaging implications. Journal of nuclear medicine: official publication, Society of Nuclear Medicine. 2011; 52:1005-8.

23. Ruiz-Perez MV, Sanchez-Jimenez F, Alonso FJ, et al. Glutamine, glucose and other fuels for cancer. Current pharmaceutical design. 2014; 20:2557-79.

24. Kit S. The biosynthesis of free glycine and serine by tumors. Cancer research. 1955;15:7158.

25. Pollari S, Kakonen SM, Edgren H, et al. Enhanced serine production by bone metastatic breast cancer cells stimulates osteoclastogenesis. Breast cancer research and treatment. 2011; 125:421-30.

26. Locasale JW, Grassian AR, Melman T, et al. Phosphoglycerate dehydrogenase diverts glycolytic flux and contributes to oncogenesis. Nature genetics. 2011;43:869-74.
27. Ojala P, Sundström J, Grönroos JM, et al. mRNA differential display of gene expressionin colonic carcinoma. Electrophoresis. 2002;23:1667-76.

28. Vié N, Copois V, Bascoul-Mollevi C, et al. Overexpression of phosphoserine aminotransferase PSAT1 stimulates cell growth and increases chemoresistance of colon cancer cells. Mol Cancer. 2008; 7:14.

29. Yoon S, Kim JG, Seo AN, et al. Clinical Implication of Serine Metabolism-Associated Enzymes in Colon Cancer. Oncology. 2015;89:351-9.

30. Yan S, Jiang H, Fang S, et al. MicroRNA-340 Inhibits Esophageal Cancer Cell Growth and Invasion by Targeting Phosphoserine Aminotransferase 1. Cell Physiol Biochem. 2015;37:375-86.

31. Yang Y, Wu J, Cai J, et al. PSAT1 regulates cyclin D1 degradation and sustains proliferation of non-small cell lung cancer cells. Int J Cancer. 2015;136:E39-50. 